\title{
Electron spin resonance dating of fault gouge from Desamangalam, Kerala: Evidence for Quaternary movement in Palghat gap shear zone
}

\author{
T K Gundu Rao, C P Rajendran*, George Mathew ${ }^{\dagger}$ and Biju John J $^{\ddagger}$ \\ R.S.I.C., Indian Institute of Technology, Powai, Mumbai 400 076, India \\ ${ }^{*}$ Centre for Earth Science Studies, Akkulam, Thiruvananthapuram 695 031, India \\ ${ }^{\dagger}$ Department of Geology, M.S. University of Baroda, Vadodara 390 002, India \\ ${ }^{\ddagger}$ Geological Survey of India, Northern Region, Lucknow 226 020, India
}

\begin{abstract}
The field investigations in the epicentral area of the 1994 Wadakkancheri (Desamangalam), Kerala, earthquake (M 4.3) indicate subtle, but clearly recognizable expressions of geologically recent fault zone, consisting of fracture sets showing brittle displacement and a gouge zone. The fracture zone confines to the crystalline basement, and is spatially coincident with the elongation of the isoseismals of the 1994 mainshock and a 10-km-long WNW-ESE trending topographic lineament. The preliminary results from the electron spin resonance (ESR) dating on the quartz grains from the fault gouge indicate that the last major faulting in this site occurred $430 \pm 43 \mathrm{ka}$ ago. The experiments on different grain sizes of quartz from the gouge showed consistent decrease in age to a plateau of low values, indicating that ESR signals in finer grains were completely zeroed at the time of faulting due to frictional heat. The results show a relatively young age for displacement on the fault that occurs within a Precambrian shear zone. Discrete reactivated faults in such areas may be characterized by low degree of activity, but considering the ESR age of the last significant faulting event, the structure at Desamangalam may be categorized as a potentially active fault capable of generating moderate earthquakes, separated by very long periods of quiescence.
\end{abstract}

\section{Introduction}

Geological studies in southern peninsular India have, in recent years, focused on the neotectonics and paleoseismicity (Rajendran et al 1996; Subrahmaniya 1996; Valdiya 1998). While these studies have provided new neotectonic interpretations and fault-specific data, little is known about the absolute age of penultimate faulting. Lack of this input seriously hinders proper evaluation of seismic potential of the faults in question. This problem becomes acute in the cratonic hinterland because of the fact that the damaging earthquakes occur on pre-existing faults with a recurring period of tens of thousands of years (Rajendran et al 1996; Crone et al 1997), and therefore, the historical seismicity or lack of it cannot be considered as reflective of the real seismic potential. Many faults in this region remain deceptively quiet for a very long time before it produces a damaging earthquake, without much warning. The 1993 Killari earthquake is a typical example. Such faults are primary targets of geological studies that aim at revealing the nature of fault recurrence.

However, recognizing active structures in the cratonic areas is not easy. A major problem has been the poor development of surface rupture due to faulting complexities (Rajendran 2000). In areas, categorized as stable continental regions (SCRs), where the recurrence interval is too long and erosional processes too fast, the sedimentary layers containing fault-related structures are easily

Keywords. ESR dating; fault gouge; neotectonism; paleoseismology; Palghat gap. 
removed, thus destroying the surficial evidence of faulting. Another problem is the subtle nature of the geomorphic indicators, which hinders recognition and dating of paleo-earthquakes. Lack of well-developed sequence of overlying sediment/soil profile is another problem specific to exhumed crystalline rocks within the Precambrian shear zones. Lateritization and the associated weathering processes can also obscure or camouflage most of the deformational features.

Our recent studies in the reactivated zones within a Precambrian shear belt along the Palghat gap region, however, suggest that evidence of geologically young faulting events might be found in fault breccia and gouge within the fractures, present in the upper levels of exhumed crystalline rocks (John and Rajendran 2002). These intrafault materials are apparently formed due to frictional sliding of fault blocks, which is always accompanied by damage and erosion of slip surfaces, a process that is known as wear, which also generates frictional heat (e.g., see Sibson 1977 and Scholz 1990, and references therein, for discussion on various types of fault rocks and their deformation mechanisms). Ideally, determining the age of these intrafault materials by appropriate techniques should yield the date of the last faulting event.

Different methods including fission track dating, $\mathrm{K}-\mathrm{Ar}$ and $\mathrm{Rb}-\mathrm{Sr}$ methods have been employed to constrain the age of the intrafault material. But these methods are limited by their lack of resolving power for rocks younger than $2 \mathrm{Ma}$ (see Noller et al 2000 and references therein). Zeller (1968) first introduced electron spin resonance (ESR) method that could be used to determine the age of geologically younger materials. Ikeya et al (1982) developed this method further, and demonstrated that the timing of fault movement with a maximum range of $1 \mathrm{Ma}$ could be determined by electron spin resonance (ESR) using $E^{\prime}$ (e-prime) and $\mathrm{OHC}$ (oxygen hole-) centres in quartz.

\section{ESR method}

In the dating of fault gouge material, it is essential that the ESR signals of inherent defect centres in the quartz grains reset to zero. The stress and the frictional temperature active on the fault plane at the time of faulting are expected to reset the ESR signals of several centres to zero level. After the faulting episode, the ionizing radiations regenerate signals due to natural radioactivity that grows monotonically with increasing dose in a known manner. The final concentration of defects is proportional to the total amount of natural radiation received by the sample after the faulting event. The
ESR age, $T$, can be calculated by applying the following formula,

$$
T=A D / D,
$$

where, $A D$ is the accumulated dose of natural radiation in quartz (in Gy) that the sample has accumulated since last resetting/faulting, and can be determined by the additive dose method. The accumulated dose $A D$ is evaluated by the ESR intensity, since the intensity of ESR signal is proportional to the number of lattice defects or trapped electrons. $D$ is the radiation dose rate (Gy/ka) to which the sample has been exposed. The radiation dose rate $D$ can be determined by measuring either the concentration of radioactive elements within the fault gouge or the radioactivity by a thermoluminescence dosimeter (TLD) buried within the fault gouge.

The objective of the present study was to test the electron spin resonance (ESR) method on fault gouge, collected from a fault outcrop near Desamangalam, Thrissur District, Kerala State (figure 1). We discuss the preliminary results of ESR experiments to constrain the possible age of the last faulting event at Desamangalam, and its implications for neotectonic activity.

\section{Geology of the study area}

Our study area lies in the southern flank of the Palghat gap, a conspicuous E-W trending geomorphic feature within in the southern granulite terrain (figure 1). Both macroscopic and microscopic features suggest that this region is a Precambrian shear zone, defined by a large EW-dextural oblique-slip component (D'Cruz et al 2000). Thermobarometric studies indicate largescale tectonic exhumation of lower to mid-crustal rocks within this shear zone (Ravindrakumar and Chacko 1994). The present topography, consisting of a $250-\mathrm{km}$-long and $30-\mathrm{km}$-wide low land bordered by ridges and hills, is believed to have resulted from the combined action of shearing and erosion. An antecedent river, called Bharathapuzha, occupies the middle part of the low land, whose course is apparently controlled by the linearity of the shear zone.

The major rock type at Desamangalam is charnockite, and it shows well-developed south dipping foliation trending in WNW-ESE direction. Extensive joint sets have also developed throughout the area; biotite-rich foliations serve as the weaker planes for the development of these joints. A few exposures show 3-5-cm-thick patches of biotite schist, which are oriented parallel to the regional foliation direction. Quartzo-feldspathic 


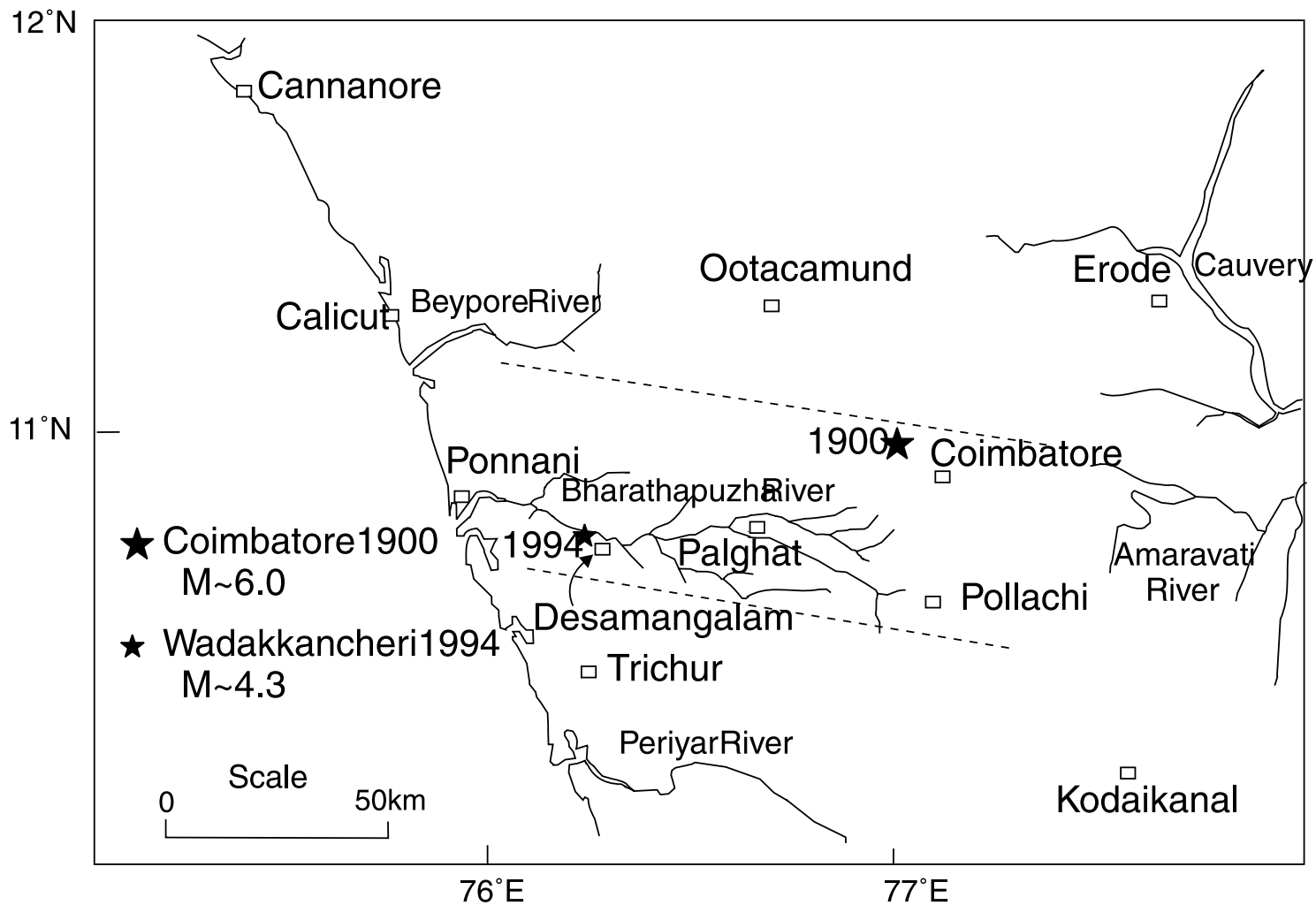

Figure 1(a). Index map of study area. Lateral extent of the Palghat gap shear zone is shown by dashed line (after Subrahmaniam and Muraleedharan 1985).

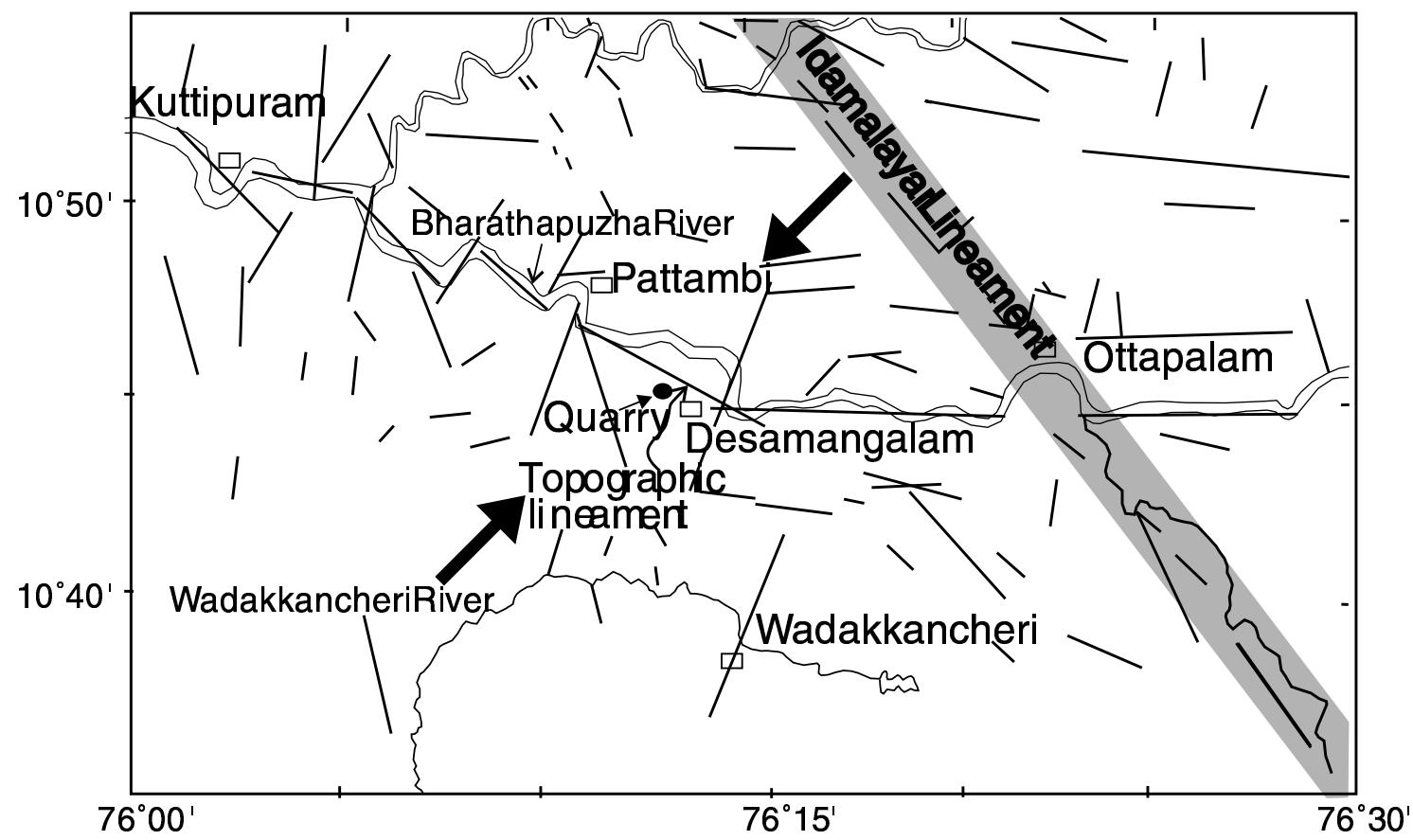

Figure 1(b). Map showing linear structures of the area, prepared using satellite imagery, air photos and topographic maps. Solid arrows denote inferred direction of compressional stresses.

veins have intruded into the parent rocks that occur both parallel and perpendicular to the foliation direction. These veins may have been associated with a major phase of emplacement in the
Palghat gap region, dated at 484-512 Ma (Soman et al 1990). We observed numerous semi-brittle offsets $(0.5 \mathrm{~m})$ in these veins. Most of them are oriented perpendicular to the foliation direction 
(WNW-ESE) and show a dextral strike-slip sense of movement, indicating that the region has undergone several cycles of Precambrian tectonics. Alternatively, it may also suggest occurrence of subsidiary faults in association with major E-W trending fault zone.

\section{Local seismicity}

The eastern terminus of the Palghat gap has been a site of a moderate earthquake $(M \leq 6)$ in the past (1900, Coimbatore) (figure 1a). The epicentre of the 1994 event (M 4.3) was located at Desamangalam $\left(10^{\circ} 45^{\prime} \mathrm{N}\right.$ and $\left.76^{\circ} 15^{\prime} \mathrm{E}\right)$ on the left bank of the Bharathapuzha River (Rajendran and Rajendran 1996) (figure 1), which occurs to the western end of the gap. The recent activity at Desamangalam (near Wadakkancheri town), in spite of its low magnitude, commanded attention because of its conspicuous spatial association with a regional structure. The historic and recent seismicity of the region bears out the fact that there are potential faults in and around the gap region (Rajendran and Rajendran 1996).

The 1994 main shock that occurred in the vicinity of the rectangular bend of the Bharathapuzha
River, near Desamangalam (figure 1), is believed to be a structural feature (Rajendran and Rajendran 1996). The intensity survey conducted immediately after the earthquake indicated that the activity was concentrated along the southern bank of the Bharathapuzha River. A major topographic lineament, WNW-ESE, passes through this area (figure 1b). This lineament is defined by the linearity of a group of hills, which also appears to control the course of Bharathapuzha River, as it reaches the epicentral area. Elongation of the isoseismals of the 1994 mainshock roughly coincides with the trend of the topographic lineament.

\section{Fault zone at Desamangalam}

A quarry in one of the hills that forms the part of the topographic lineament at Desamangalam exposed a 6 -m-wide zone of fractures (figure 1b), which shows a strike direction of WNW-ESE, dipping $45^{\circ}$ toward south, parallel to the regional foliation. These fracture sets exhibit evidence of slip, including slickensides, mineral striations, breccia, gouge and recognizable offset (John and Rajendran 2002). Because of the aforementioned features we prefer to qualify this area as a 'fault zone'. Similar

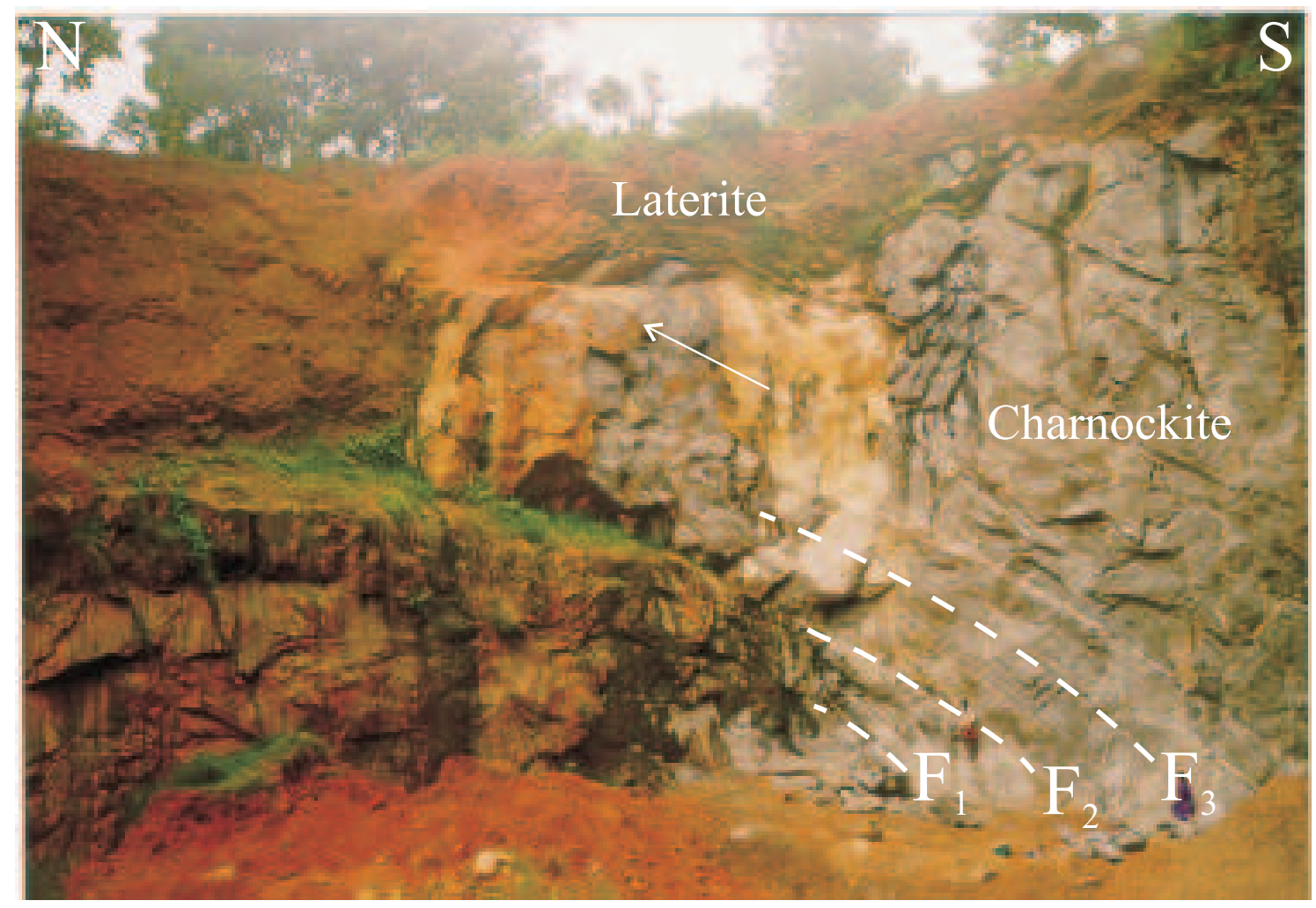

Figure 2(a). Fault-zone at Desamangalam quarry face demarcated by fractures F1, F2 and F3. Fracture F2 shows indicators such as displacement of marker horizons and generation of gouge. Note the development of laterite on the top of the crystalline rock. The fractures have not apparently extended to the laterite, indicating its later development. Arrow indicates northward thrust movement of the fault block. 


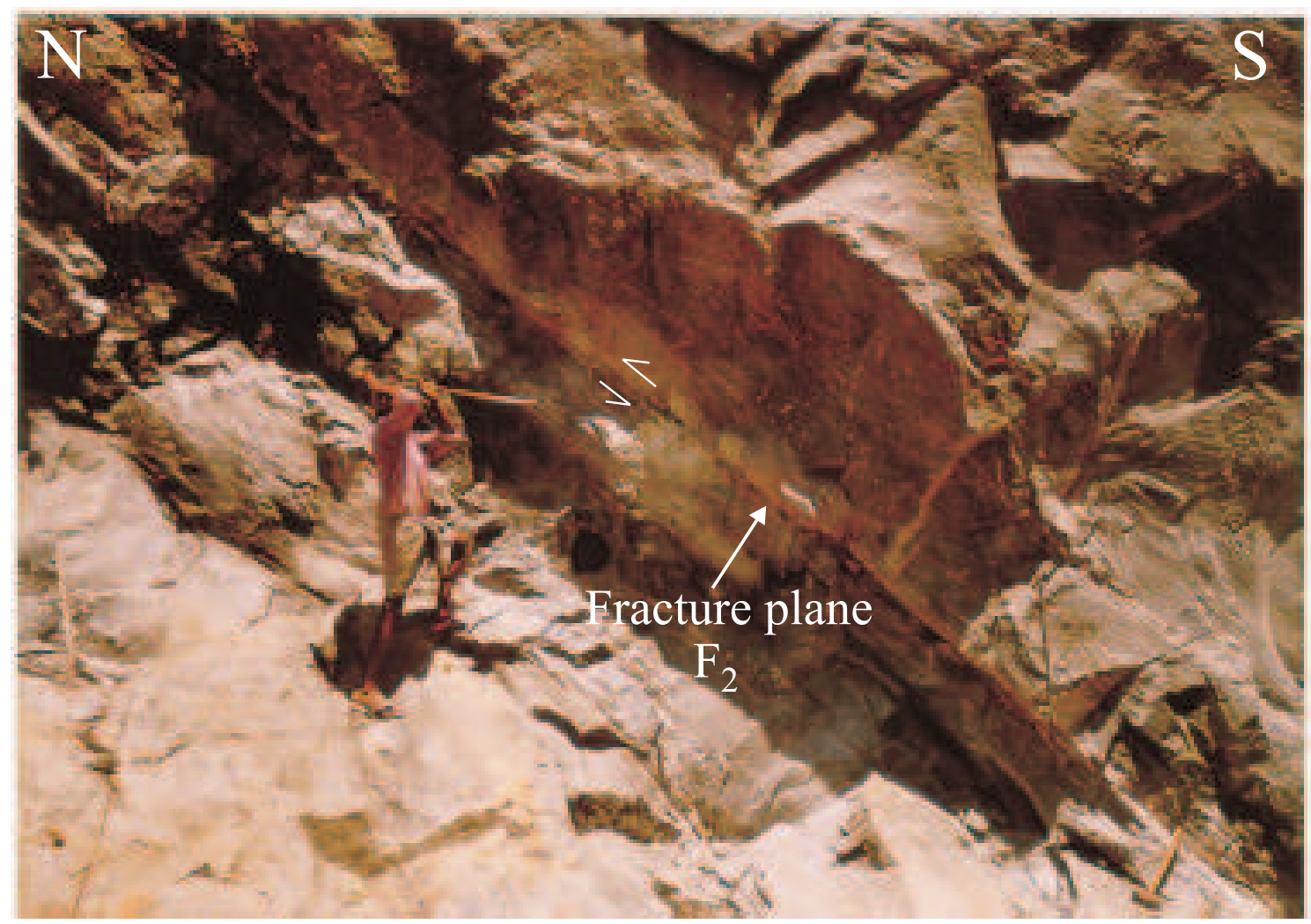

Figure 2(b). A close-up view of the fracture F2. Weathered and wet gouge material composed of minute rock pieces and clay occurs between the fracture planes. Coupled arrows indicate fault movement.

fault zones within the crystalline rocks have been identified elsewhere, which are characterized by suites of fractures that show evidence of brittle displacement (Dawers and Seeber 1991).

The fault zone at Desamangalam is $5.5-6 \mathrm{~m}$ wide (figure 2a), and consists of three parallel fractures (figure 2a). Fracture F1 does not show much displacement, probably because it passes through a zone of high concentration of biotite, showing schistocity that is susceptible to shearing. However, a number of microfractures have developed, parallel to $\mathrm{F} 1$ in this zone, most of them showing lineations and striations indicative of a northward movement.

The fracture F2 displays a slip plane with visible evidence of movement (figures 2a and b), including a variety of brittle deformation structures. The long axes of grooves and striations of the slip plane conform to an oblique reverse sense of movement. Crushed rock and cavities occur along the contact surface; a few of the cavities are filled with secondary minerals. The fault contact has developed a 6-cm-thick gouge zone, distributed uniformly throughout the slip surface. Two sets of striations are found in this zone - the first set may have resulted from a perfect reverse movement and the latter set from an oblique movement. Apparent displacement along the slip plane is measured to be $25 \mathrm{~cm}$, based on the offset along a vein. Calculating the actual amount of slip is difficult because the orientation of the vein could not be constrained with respect to the fault plane. Moreover, the actual slip direction is characterized by a combination of both oblique and reverse movements. The F3 fracture occurs at a higher level (figure 2a), parallel to the F2 fracture. The striations present within the fracture plane, indicate a northward oblique reverse movement.

The trend of the fracture zone is spatially coincident with the isoseismal elongation of the 1994 earthquake that in turn aligns with a prominent topographic lineament (figure 1a). This lineament is inferred to be representing the updip trace of the above mentioned fault zone. Paleochannels, meander scrolls and rapids, possibly indicating rejuvenation of the landscape occur on the southern bank of the Bharathapuzha river. Our inferences on the sense of motion obtained from brittle structures, indicating a northward thrust movement, are also consistent with the neotectonic kinematics, controlled possibly by the prevailing compressional stresses (John and Rajendran 2002).

\section{Analytical procedures}

Samples were collected along the fracture plane F2 (figure $2 \mathrm{~b}$ ), after scraping the exposed part. The 
highly weathered sample was stored in black plastic bags to avoid any loss of water and exposure to light. After calculating the water content in the sample, the material was opened in a darkroom and was dried in the oven, disaggregated, and sieved for various fractions. After magnetic separation, the sample was dissolved using $40 \% \mathrm{HF}$ for one hour to remove materials other than quartz. It was then cleaned with concentrated $\mathrm{HCl}$ to remove fluoride ions. The sample was again washed with dilute $\mathrm{HCl}$ for one hour followed by washing with water four to five times and finally dried in a dark room. We used single aliquot of $200 \mathrm{mg}$ of various grain sizes $(37,43,53,63,74$ and $100 \mu \mathrm{m})$ for irradiation with ${ }^{60} \mathrm{Co}$ source. The gamma dose rate was $31 \mathrm{~Gy} / \mathrm{min}$.

We carried out ESR measurements on a varian E-112 E-line Century Series X-band ESRspectrometer, which utilizes $100 \mathrm{kHz}$ field modulation. Tetracyanoethylene (TCNE, g = 2.00277) was used as a standard for $g$-factor measurements. A varian variable temperature accessory was used to carry out experiments at different temperatures.

The annual dose rate $D$ in the fault gouge was measured on the basis of $\mathrm{ZnS}$ (As) alpha counting. Th and $\mathrm{U}$ were determined by gross alpha counting technique, using pairs circuit (e.g., Aitken 1985), and the potassium content by using inductively coupled plasma-atomic emission spectroscopy (ICP-AES). The cosmic radiation component and wetness were assumed to be $0.15 \mathrm{mGy} / \mathrm{a}$ and $5 \%$, respectively. Accumulated dose $(A D)$ estimates of individual grain size are an average of five aliquots and the error in $\mathrm{AD}$ was found to be $\pm 10.15 \%$. The error in ESR age was found to be $\pm 10.3 \%$ and the error estimation has been done taking into consideration the individual errors (table 1).

The ESR spectra of quartz are complex and generally five types of ESR signals can be distinguished in quartz. The centres associated with these signals are characterized by distinct $g$-factors.
The $E^{\prime}$, Ge and OHC centres are characterized by $g$ factors $2.001,1.997$ and 2.011, respectively and the corresponding ESR signals are observable at room temperature. The $\mathrm{Al}$ centres are associated with $g=2.060, g=2.0083$ and $g=2.0017$, while $g=1.979, g=1.931$ and $g=1.913$ correspond to $\mathrm{Ti}$ centre. Observable at low temperatures, these centres are usually recorded at $100 \mathrm{~K}$. The $\mathrm{OHC}$ and $E^{\prime}$ signals observed in the present fault gouge sample are shown in figure 3 . The following spectrometer settings were used for these experiments; microwave frequency: $9.08 \mathrm{GHz}$, scan width: $100 \mathrm{G}$, modulation frequency: $100 \mathrm{kHz}$ and modulation amplitude: 0.5 gauss. As $E^{\prime}$ centre saturates at low microwave powers, $0.1 \mathrm{~mW}$ power was used for $E^{\prime}$ related experiments, while OHC signals were recorded at $5.0 \mathrm{~mW}$ power. Ge centre was not observed in the natural samples as well as in the laboratory irradiated samples. Because Al centers have short spin lattice relaxation at room temperature, Al spectra were obtained at $80 \mathrm{~K}$ with $2.0 \mathrm{~mW}$ microwave power. ESR intensity of Al signals was measured from the lower point on line 1 to the highest point on line 4 (figure 4), as suggested by Yokoyama et al (1985) and Porat and Schwarz (1991) as against between 1st and 14th hyperfine lines. The component between 6 th and 9th hyperfine lines of Al centre strongly overlaps with the peroxy signal (Lee and Schwarcz 1993), and are not affected by $\gamma$-ray irradiation. This, therefore, affects the determination of peak-to-peak intensity for AD measurement. The ESR signals corresponding to $\mathrm{OHC}$ and $E^{\prime}$ centres are the most frequently used signals for the dating of fault gouge.

A random analysis of the gouge material does not necessarily indicate whether the quartz grains have been fully reset or zeroed by the displacement event. Schwarcz et al (1987) and Buhay et al (1988) were the first to observe a positive correlation between decreasing AD with decreasing grain size. They proposed that during the faulting event

Table 1. ESR analytical data for different grains size fractions of fault gouge from Desamangalam.

\begin{tabular}{|c|c|c|c|c|c|c|c|c|}
\hline $\begin{array}{l}\text { Sample } \\
\text { no. }\end{array}$ & $\begin{array}{l}\text { Sieve mesh } \\
\text { size }(\mu \mathrm{m})\end{array}$ & $\begin{array}{l}\text { Defect } \\
\text { centre }\end{array}$ & $\mathrm{U}(\mathrm{ppm})$ & Th (ppm) & $\mathrm{K}(\mathrm{wt} \%)$ & $\begin{array}{c}\text { Dose (D) } \\
(\mathrm{Gy} / \mathrm{ka})\end{array}$ & $\begin{array}{l}\text { Accumulated dose } \\
\text { (AD) (Gy) }\end{array}$ & $\begin{array}{l}\text { Age (ka) } \\
T=A D / D\end{array}$ \\
\hline CPR1 & $\begin{array}{r}100 \\
74 \\
63 \\
53 \\
43 \\
37\end{array}$ & $\begin{array}{l}E^{\prime} \\
E^{\prime} \\
E^{\prime} \\
E^{\prime} \\
E^{\prime} \\
E^{\prime}\end{array}$ & $0.805 \pm 0.06$ & $3.841 \pm 0.19$ & $2.5 \pm 0.10$ & $2.71 \pm 0.32$ & $\begin{array}{l}2441 \pm 219 \\
2056 \pm 185 \\
1880 \pm 169 \\
1361 \pm 122 \\
1155 \pm 103 \\
1180 \pm 106\end{array}$ & $\begin{array}{l}900 \pm 92 \\
758 \pm 78 \\
693 \pm 71 \\
502 \pm 51 \\
426 \pm 43 \\
435 \pm 44\end{array}$ \\
\hline CPR1 & $\begin{array}{r}100 \\
74 \\
63 \\
53 \\
43 \\
37\end{array}$ & $\begin{array}{l}\mathrm{Al} \\
\mathrm{Al} \\
\mathrm{A} 1 \\
\mathrm{Al} \\
\mathrm{Al} \\
\mathrm{A} 1\end{array}$ & $0.805 \pm 0.06$ & $3.841 \pm 0.19$ & $2.5 \pm 0.10$ & $2.71 \pm 0.32$ & $\begin{array}{c}2836 \pm 255 \\
2148 \pm 193 \\
1446 \pm 130 \\
1268 \pm 114 \\
1280 \pm 115 \\
-\end{array}$ & $\begin{aligned} & 1046 \pm 107 \\
& 792 \pm 81 \\
& 533 \pm 54 \\
& 467 \pm 48 \\
& 472 \pm 48 \\
&-\end{aligned}$ \\
\hline
\end{tabular}




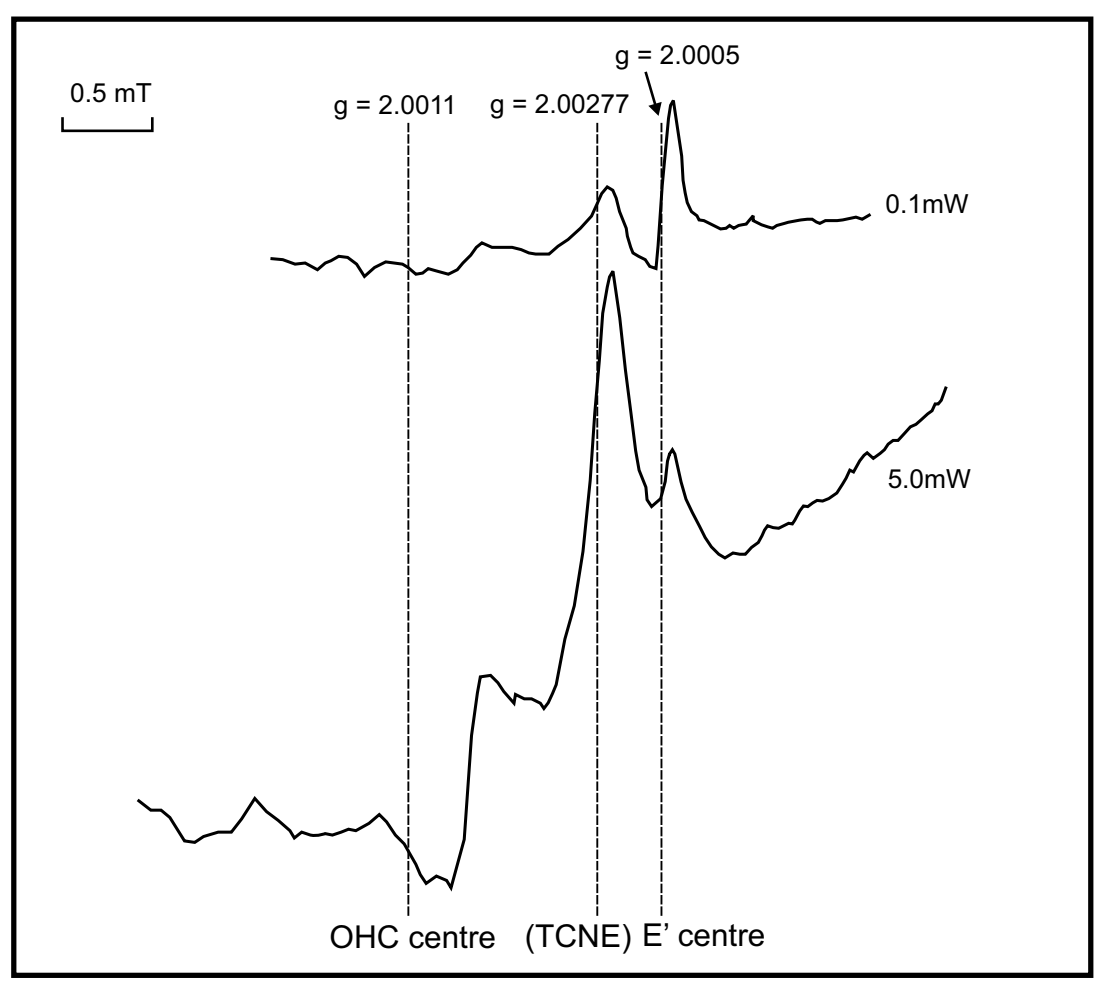

Figure 3. Room temperature ESR spectrum of $E^{\prime}$-centre and OHC centre of quartz from fault gouge sample. The microwave power is $0.1 \mathrm{~mW}$ for $E^{\prime}$-centre and $5 \mathrm{~mW}$ for OHC centre.

the finer grains are more stressed than the coarser grains. Lee and Schwarz (1994a and b) demonstrated the criteria of the plateau test using different grains sizes for $E^{\prime}, \mathrm{OHC}$ and $\mathrm{Al}$ centres to verify for complete resetting. The main inference of plateau test is that the grains smaller than some critical radius would be totally reset, while the larger grains and stable ESR centres would be only partially reset. Fukuchi et al (1986) suggest that complete resetting is indicated by similar ages by multiple centers if they are zeroed completely, and therefore, will yield a concordant age.

In the present study on fault gouge sample from Desamangalam, $E^{\prime}, \mathrm{Al}$, and Ti centers were discerned in $100 \mu \mathrm{m}$ grains, whereas in the smaller grain fractions, Ti impurity was not clearly resolved. Similarly, the OHC centers indicated poor resolution for different grain sizes. ESR experiments on $E^{\prime}$ and $\mathrm{Al}$ centres for different grain sizes showed consistent decrease in age (figures 5 and $6)$. The ages estimates of smaller grain fractions, lying on the partial plateau, below $43 \mu \mathrm{m}$ mesh size would be the true ages of the last displacement event (figure 6), and the ages of larger grains indicate a partial resetting of ESR signals at the time of movement of fault blocks. The age of Desamangalam fault gouge is calculated using $E^{\prime}$ signal as a measure of mean age between grains of 43 and $37 \mu \mathrm{m}$ size, showing a partial plateau (figure 6).
This plateau corresponds to the age of the last movement.

\section{Implications for tectonism}

The preliminary results indicating a mean ESR date of $430 \pm 43 \mathrm{ka}$ (figure 5) for the gouge suggests that the fault at Desamangalam was active during the mid-Quaternary period. Considering the low seismic activity in the mid-cratonic regions, this result itself is not surprising. What is important to note here is the fact that certain discrete faults in the Precambrian shear zone are susceptible to stress loading even in the geologically recent past. One question that needs to be resolved is the magnitude of the last earthquake, which reset the ESR signals. It was difficult to estimate the actual amount of displacement at the sampling site, because of the rarity of marker horizons in massive charnockitic rocks. Since we do not have the actual amount of displacement, the empirical relationship between offset and magnitude cannot be used here.

According to some laboratory tests of zeroing of ESR signals, the normal stress and shear strain (displacement) needed for complete resetting of a $0.5 \mathrm{~mm}$ layer of mixture of quartz and kaolinite is $50 \mathrm{~cm}$ displacement (shear strain $=1000)$ under a normal stress of $2 \mathrm{MPa}$ (Ariyama 1985). Besides, a functional relationship developed by Engelder 


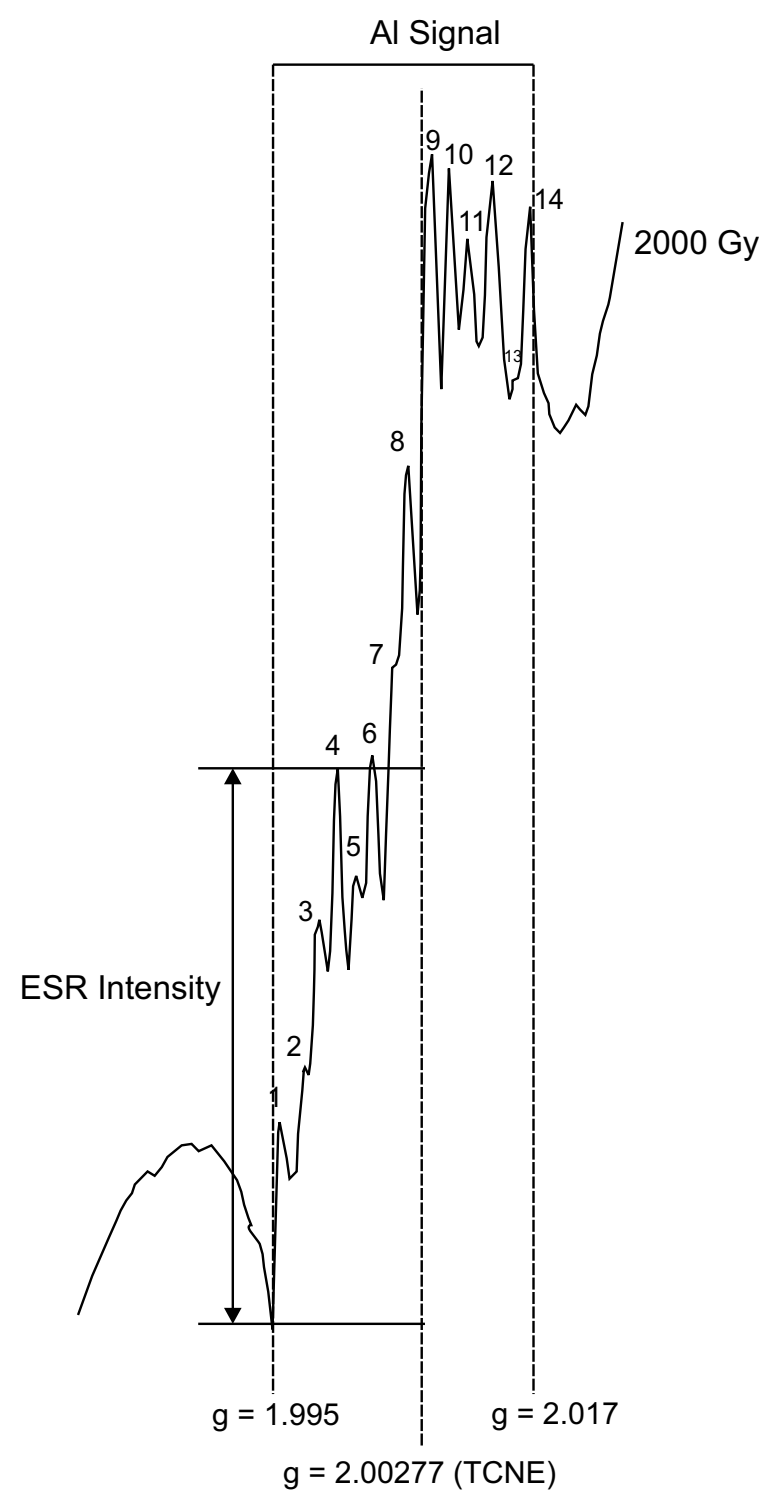

Figure 4. ESR spectrum at $93 \mathrm{~K}$ of $\mathrm{Al}$ centre in quartz from fault gouge, showing procedure for peak-to-peak intensity measurement between the 1st and 4th hyperfine lines.

(1974) can also be used to decipher displacement based on the thickness of gouge.

$$
d_{s}=8 t,
$$

where, $d_{s}(\mathrm{~cm})$ is the shear displacement and $t(\mathrm{~cm})$ is the mean thickness of the gouge zone. The volume (thickness) of gouge is assumed to increase incrementally during sliding events. Using this simple linear relation, the 6 -cm-thick gouge zone at Desamangalam suggests about $50 \mathrm{~cm}$ of displacement.

Sibson (1989) calculated that the mean slip can range between $1 \mathrm{~mm}$ and $4 \mathrm{~mm}$ for magnitudes 1 and 8 earthquakes, respectively. For an earthquake of $M=6$, the average slip and rupture are calcu- lated to be $\sim 40 \mathrm{~cm}$ and $10 \mathrm{~km}$, respectively. Our investigations of the peninsular India earthquake at Killari (Mw 6.3) indicate a maximum near surface slip of $80 \mathrm{~cm}$ and an average slip of $50 \mathrm{~cm}$ (Rajendran et al 1996). Based on the above observations, it is reasonable to assume $M \sim 6$ as the minimum bound for the earthquake that occurred at Desamangalam, $430 \pm 43$ ka ago.

The other issue is the status of this fault in terms of the degree of activity. Can it be called an active fault? No definition for active faults is universally accepted, although two elements are present in most definitions (Slemmons and dePolo 1986): (1) the potential for future displacements in the present tectonic setting, and (2) the time of 


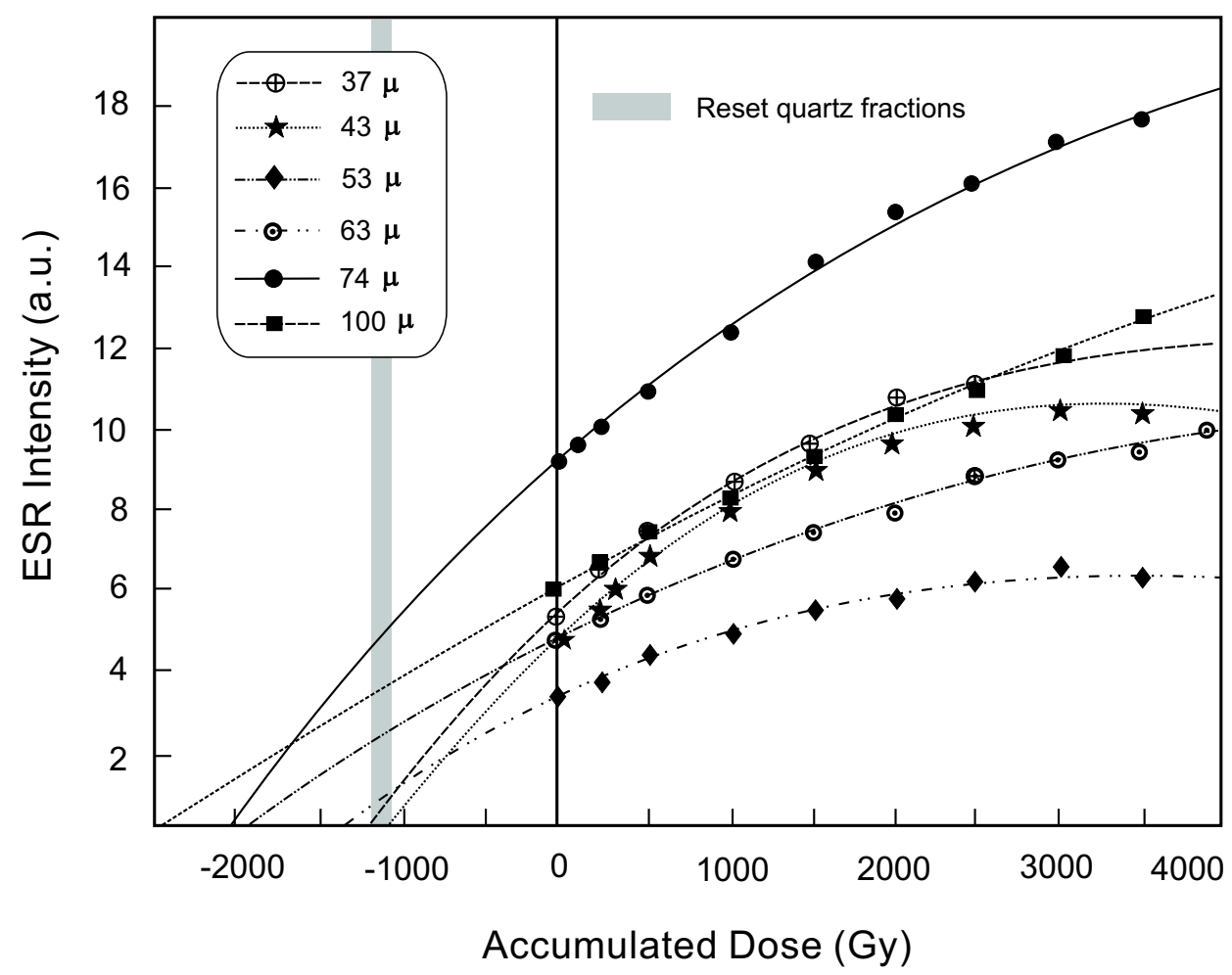

Figure 5. The growth of the ESR signal intensities of $E^{\prime}$ centre as a function of the radiation dose and the determination of $\mathrm{AD}$ by the additive method for the fault gouge sample. The different growth curves are for different grain sizes of the sample.

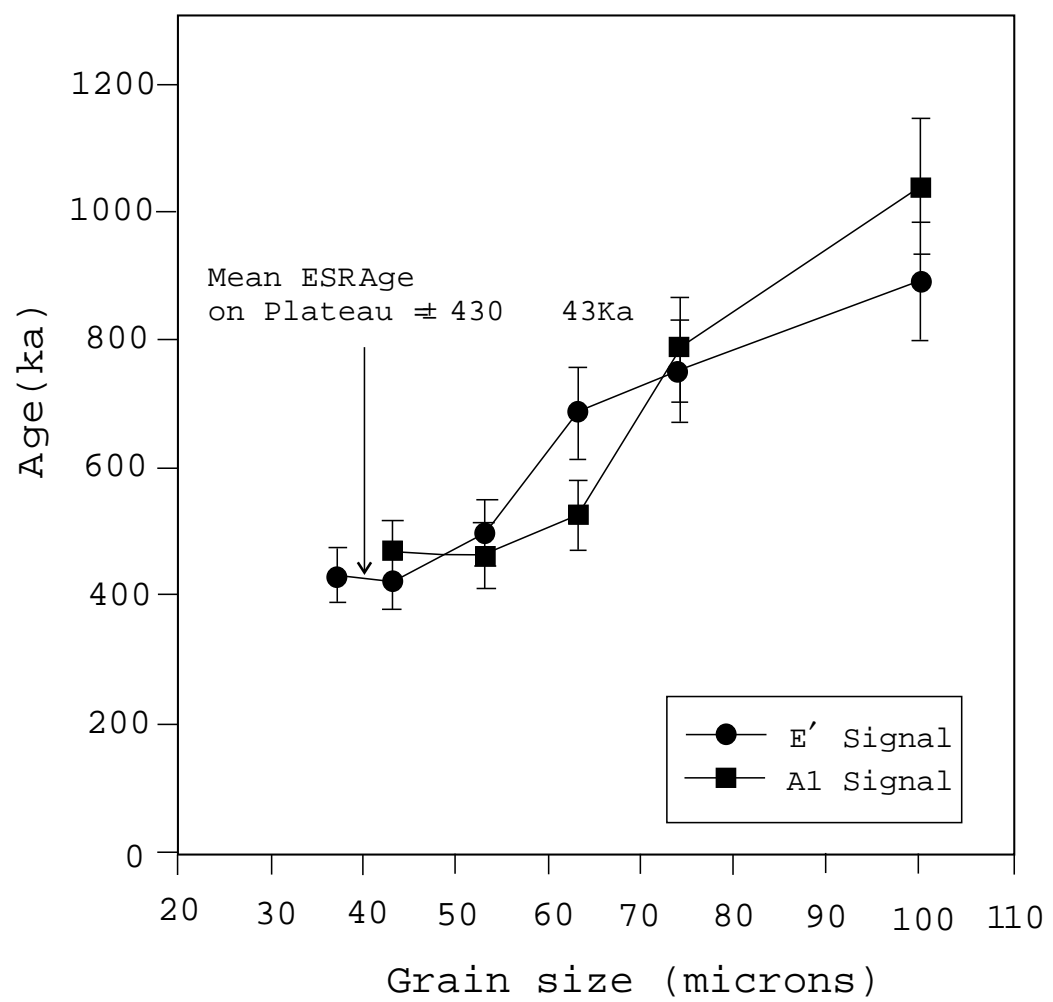

Figure 6. Plateau test of age (ka) versus grain size for $E^{\prime}$ and Al ESR signal in the Desamangalam fault gouge sample (CPR1). The age estimated is the mean age between 43 and $37 \mu \mathrm{m}$ grain size quartz fractions.

most recent displacement (e.g., historical, Holocene or Quaternary). The first element is critical to all assessments for larger earthquakes. The second element relates to the degree of activity or recency. The principles of recency as used in plate boundaries or active intraplate regions cannot be applied 
without modifications in cratonic settings (Rajendran 2000). Considering the long recurrence period and low degree of activity in such areas, we believe that fault at Desamangalam may be defined as potentially active, judging by SCR standards.

A major limitation of the present study is the lack of data from neighboring areas, which would have facilitated a comparison of results. Future studies in the area should focus on obtaining samples from additional sites to test the ESR result presented here. This study reiterates the need to reexamine the Precambrian shear zones in peninsular India for evidence of reactivation in the recent past, as these areas provide the most probable locales for stress concentration. Dating of the intrafault material from such sites using ESR techniques will take us a step closer to developing age criteria in identifying active faults within exhumed shear zones in cratonic hinterlands.

\section{Acknowledgements}

We thank Shri M Chougaonkar (Environment Assessment Division, BARC) for his help in the dose analyses. Financial support from DST, New Delhi (No.DST/23(196)/ESS/99) to T K G (Co$\mathrm{PI}$ ) is gratefully acknowledged. C P R and B J thank V Prasannakumar, G R Ravindrakumar and Kusala Rajendran for discussions during various phases of fieldwork and the Director of CESS, M Baba for his keen interest and encouragement. Our research was partly supported by the Government of Kerala grant released through the Department of Revenue. G M is grateful to CSIR and DST for RA fellowship. B J thanks CSIR for the SRF fellowship. Thanks are also due to the reviewers for constructive comments, which improved the earlier draft.

\section{References}

Aitken M J 1985 Thermoluminescence dating (New York: Academic Press) 291p.

Ariyama T 1985 Conditions of resetting the ESR clock during faulting; In: ESR dating and dosimetry, (eds) M Ikeya and N Miki Ionics, Tokyo, 249-256

Buhay W M, Schwarcz H P and Grün R 1988 ESR dating of fault gouge: the effect of grain size; Quaternary Science Reviews 7 515-522

Crone A J, Machette M N and Bowman J R 1997 Episodic nature of earthquake activity in stable continental regions revealed by palaeoseismicity studies of Australian and North American Quaternary faults; Australian J. Earth Sci. 44 203-214

Dawers N and Seeber L 1991 Intraplate faults revealed in crystalline bedrock in the 1983 Goodnow and 1985 Ardsley epicentral areas, New York; Tectonophysics 186 115131
D'Cruz E, Nair P K R and Prasannakumar V 2000 Palghat Gap-A dextral shear zone from the south Indian granulite terrain; Gondwana Res. 3 21-31

Engelder J T 1974 Cataclasis and the generation of fault gouge; Geol. Soc. Am. Bull. 85 1515-1522

Fukuchi T, Imai N and Shimokawa K 1986 ESR dating of fault movement using various defects centres in quartz, the case in the western south Fossa maggna, Japan; Earth Planet. Sci. Lett. 78 121-128

Ikeya M, Miki N and Tanaka K 1982 Dating of fault by electron spin resonance on intrafault materials; Science 215 1392-1393

John B and Rajendran C P 2002 Characteristics of brittle deformation in a Precambrian crystalline terrain and implications for active faulting: An example from Kerala, south India; Tectonophysics (in review).

Lee H K and Schwarcz H P 1993 An experimental study of shear induced zeroing of ESR signals in quartz; Applied Radiation Isotope 44 191-195

Lee H K and Schwarcz H P 1994a Criteria for complete zeroing of ESR signals during faulting of the San Gabriel fault zone, S. California; Tectonophysics 235 317-337

Lee H K and Schwarcz H P 1994b ESR plateau dating of fault gouge; Quaternary Science Reviews 12 629-634

Noller J S, Sowers J M, Lettis W R (ed) 2000 Quaternary geochronology: Methods and applications; AGU Reference Shelf 4 581p.

Porat N and Schwarcz H P 1991 Use of signal subtraction in ESR dating of burned flint. Nuclear Tracks Radiation Measurement 18 203-212

Rajendran C P and Rajendran K 1996 Low-moderate seismicity in the vicinity of Palghat Gap, south India and its implications; Current Science 70 304-307

Rajendran C P, Rajendran K and John B 1996 The 1993 Killari (Latur), central India, earthquake: An example of fault reactivation in the Precambrian crust; Geology 24 651-654

Rajendran C P 2000 Using geological data for earthquake studies: A perspective from peninsular India; Current Science (Special section: Seismology 2000) 79 1251-1258

Ravindrakumar G R and Chacko T 1994 Geothermobarometry of mafic granulites and metapelite from the Palghat gap, south India: Petrological evidence for isothermal uplift and rapid cooling; J. Metamorphic Geol. 12 479-492

Scholz C H 1990 The mechanics of earthquakes and faulting (Cambridge University Press) 439p.

Schwarcz H P, Buhay W M and Grün R 1987 Electron spin resonance (ESR) dating of fault gouge. In: Directions in Paleoseismology, (eds) A J Crone and Omdahl E M; U.S. Geol. Surv. Open File Report 87-673, 50-64

Sibson R H 1977 Fault rocks and fault mechanism; J. Geol. Soc. London 133 191-213

Sibson R H 1989 Earthquake faulting as a structural process; J. Struct. Geology 11 1-14

Slemmons D B and dePolo C M 1986 Evaluation of active faulting and associated hazards; In: Active Tectonics (Washington, D.C.: National Academy Press) $45-62$

Soman K, Tara K G, Arakelyants M M and Golubyev V N 1990 Mineral ages of pegmatites from the Palghat gap region in Kerala and tectonic significance; J. Geol. Soc. India $3582-86$

Subrahmaniam K S and Muraleedharan M P 1985 Origin of the Palghat Gap in south India - A synthesis. J. Geol. Soc. India $2628-37$

Subrahmaniya K R 1996 Active intraplate deformation in south India; Tectonophysics 262 231-241 
Valdiya K S 1998 Late Quaternary movements and landscape rejuvenation in southeastern Karnataka and adjoining Tamil Nadu in southern India shield; J. Geol. Soc. India 51 139-166

Yokoyama Y, Falgureres C and Quaegebeur J P 1985 ESR dating of quartz from quaternary sediments: a first attempt; Nuclear Tracks Radiation Measurement 10 921928

Zeller E J 1968 Use of electron spin resonance for measurement of natural radiation damage; In: Thermoluminescence of geological materials. (ed) D J McDougall (London: Academic Press) 271-279 